\title{
A Spectroscopic Study of Molecular Interaction with Phosphoryl Chloride
}

\author{
PER-OLOF KINELL, INGVAR LINDQVIST and \\ M A R G A R ETA Z A CKRISSON
}

\begin{abstract}
Institute of Physical Chemistry and Institute of Chemistry, University of Uppsala, Uppsala, Sweden
\end{abstract}

\begin{abstract}
Raman and infrared spectra of mixtures between $\mathrm{POCl}_{3}$ and a number of other molecules have been studied. Two types of interaction have been found, one tentatively described as dipole-dipole, the other as electron-pair acceptor-donor interaction.
\end{abstract}

\begin{abstract}
The phosphoryl $(\mathrm{P}-\mathrm{O})$ bond frequency in addition compounds with $\mathrm{POCl}_{3}$ 1 was first studied by Sheldon and Tyree ${ }^{1,2}$ who correlated the decrease in frequency with the donor function of oxygen in the adduct formation with different acceptor molecules. In some cases, e.g. with $\mathrm{SnCl}_{4}$ in $\mathrm{SnCl}_{4} \cdot 2 \mathrm{POCl}_{3}$, they obtained more than one infrared band in the expected phosphoryl frequency range, and explained this fact as due to the co-existence of two types of $\mathrm{POCl}_{3}$, one bonded and one free. A recent crystal structure determination ${ }^{3}$ proves, however, that both $\mathrm{POCl}_{3}$ molecules in the solid compound are bonded in a very similar way, and another explanation must be sought. We therefore decided to make a more complete spectroscopic study of the molecular interaction with $\mathrm{POCl}_{3}$, going from very weak to very strong interaction, covering a wider spectral range, using infrared and Raman spectroscopy. The present paper mainly deals with weak interaction.
\end{abstract}

\section{EXPERIMENTAL}

Chemicals. $\mathrm{POCl}_{3}, \mathrm{AsCl}_{3}$ and $\mathrm{C}_{6} \mathrm{H}_{5} \mathrm{COCl}$ were purified by distillation. (B. p. $+105^{\circ}$, $+129^{\circ}$, and $+197^{\circ} \mathrm{C}$.) $\mathrm{CCl}_{4}, \mathrm{CS}_{2}, \mathrm{CHCl}_{3}$ and $1,2-\mathrm{C}_{2} \mathrm{H}_{4} \mathrm{Cl}_{2}$ were purified by fractional distillation $\left(76^{\circ}-77^{\circ}, 46.5^{\circ}, 61^{\circ}-63^{\circ}\right.$ and $\left.83^{\circ}-84^{\circ} \mathrm{C}\right)$. $\mathrm{SnCl}_{4}$ and $\mathrm{SbCl}_{5}$ were purified according to Dodd and Robinson 4. $\mathrm{SbCl}_{3}$ was purified by sublimation.

Spectroscopic measurements. The Raman spectra, excited by $\mathrm{Hg} 4358 \AA$, were photographed using an E 612 Hilger spectrograph equipped with two glass prisms and a camera having an aperture of $\mathrm{f} / 5.7$ (Exposure times $1-2 \mathrm{~h}$ ). The illuminating system consisted of a Toronto type helical mercury lamp. A saturated solution of sodium nitrite in water was used as a filter. The temperature was $20^{\circ} \mathrm{C}$. The spectroscopic arrangement is de-

Acta Chem. Scand. 13 (1959) No. 6 
scribed by Kinell s. Normally a Raman tube containing $20 \mathrm{ml}$ was used. When the amount of solution was small, a $5 \mathrm{ml}$ tube could be utilized. The tubes were filled very carefully in order to avoid as far as possible any contact between the liquids and moisture. For that purpose each tube had a ground joint by means of which it could be attached to the container holding the liquids.

The Ilford Zenith super sensitive plates used were processed with Kodak D-76 fine grain developer. The positions of the Raman lines were determined using Hartmann's disperson formula. As reference lines $\mathrm{Hg} 4$ 077, 4339 and $4916 \AA$ were selected. Measurements were as far as possible made on several exposures for the same solution. The accuracy of the wave numbers is $\pm 1-3 \mathrm{~cm}^{-1}$, depending upon the shape of the line. In a few cases the lines were too weak to be measured in the comparator. The positions of such lines have been estimated approximately and are especially marked (with circles) in the figures. No measurements of the band width and the intensities were made. The spectral slit width was $5-10 \mathrm{~cm}^{-1}$.

The infrered spectra were recorded on a Perkin-Elmer Model 21 Spectrophotometer equipped with $\mathrm{NaCl}, \mathrm{KBr}$ and $\mathrm{CsBr}$ prisms (in the Institute of Biochemistry). The spectra were run with the solutions in thin layers between two KBr plates. The spectral slit width was $3 \mathrm{~cm}^{-1}$.

\section{RAMAN SPECTRA OF POCl $_{3}$ MIXED WITH SOME OTHER MOLECULES}

The following molecules, in order of increasing dipole moment and dielectric constant, have been studied: $\mathrm{CS}_{2}=\mathrm{CCl}_{4}<\mathrm{CHCl}_{3}<1,2-\mathrm{C}_{2} \mathrm{H}_{4} \mathrm{Cl}_{2}<\mathrm{AsCl}_{3}=$ $=\mathrm{C}_{5} \mathrm{H}_{5} \mathrm{~N}<\mathrm{C}_{6} \mathrm{H}_{5} \mathrm{COCl}<\mathrm{SbCl}_{3} . \mathrm{POCl}_{3}$ would come between $\mathrm{C}_{5} \mathrm{H}_{5} \mathrm{~N}$ and $\mathrm{C}_{6} \mathrm{H}_{5} \mathrm{COCl}$ in this sequence and the spectrum of pure liquid $\mathrm{POCl}_{3}$ has been placed accordingly in Fig. 1 showing the $\mathrm{POCl}_{3}$ frequencies in the different mixtures. (A few lines could not be measured because of overlap with the spectrum of the other molecules.)

The very interesting molecules $\mathrm{SO}\left(\mathrm{CH}_{3}\right)_{2}, \mathrm{SeOCl}_{2}, \mathrm{CH}_{3} \mathrm{CN}$ and $\mathrm{C}_{6} \mathrm{H}_{5} \mathrm{CN}$ were also tried but gave complicating chemical reactions with $\mathrm{POCl}_{3}$.

A brief summary and discussion of the results is given in the following.

1. The shifts in the four lowest frequencies are very small. The largest shift is obtained with $\mathrm{SbCl}_{3}$ for the symmetrical $\mathrm{P}-\mathrm{Cl}$ bond vibration frequency, $486 \mathrm{~cm}^{-1},\left(+7 \mathrm{~cm}^{-1}\right)$.

2. The antisymmetrical P-Cl bond vibration frequency, $584 \mathrm{~cm}^{-1}$, is shifted towards higher frequencies with all solvents except $\mathrm{C}_{5} \mathrm{H}_{5} \mathrm{~N}$, the largest shifts being found with $\mathrm{AsCl}_{3}\left(13 \mathrm{~cm}^{-1}\right)$ and $\mathrm{SbCl}_{3}\left(20 \mathrm{~cm}^{-1}\right)$.

3. The symmetrical phosphoryl bond vibration frequency, $1297 \mathrm{~cm}^{-1}$, shows both positive and negative shifts. The largest positive shift is obtained with the nonpolar $\mathrm{CCl}_{4}\left(7 \mathrm{~cm}^{-1}\right)$, the largest negative shifts with $\mathrm{AsCl}_{3}\left(13 \mathrm{~cm}^{-1}\right)$ and with $\mathrm{SbCl}_{3}\left(29 \mathrm{~cm}^{-1}\right)$.

4. There is obviously no direct correlation between dipole moment and shift. It has been pointed out, however, that a dipole-dipole interaction depends also upon the charge distribution in the molecules ${ }^{6}$.

5. Fig. 1 shows that $\mathrm{AsCl}_{3}$ and $\mathrm{SbCl}_{3}$ are exceptional compared with the other molecules. These two molecules differ in two respects from the others. Their molecular shapes offer good opportunities for approach to the center of the positive charge in the dipole, their charge distributions are thus favourable for dipole-dipole interaction. They are, however, also the only possible acceptor molecules (Lewis acids) among the compounds studied. 


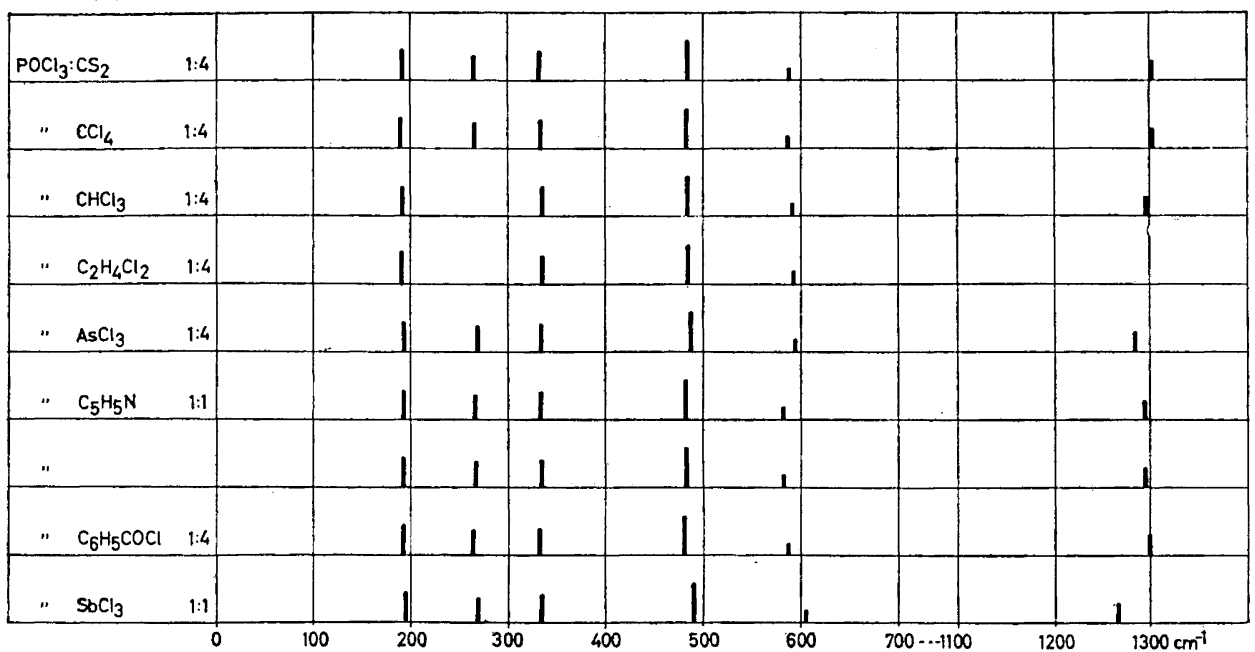

Fig. 1. Raman spectra of $\mathrm{POCl}_{3}$ in different mixtures.

These two attributes are thus inseparable in this case. This is not the rule, however, as most Lewis acids are nonpolar molecules like $\mathrm{SnCl}_{4}$ and $\mathrm{SbCl}_{5}$.

6. The increase in the antisymmetrical $\mathrm{P}-\mathrm{Cl}$ bond frequency has an analogy in the increases of the antisymmetrical $\mathrm{C}-\mathrm{C}$ chain vibration frequency obtained by compound formation between acetone and acceptor molecules like $\mathrm{BF}_{3}\left(52 \mathrm{~cm}^{-1}\right)$ or $\mathrm{AlBr}_{3}\left(40 \mathrm{~cm}^{-1}\right)^{7,8}$.

7. The large decreases in the symmetrical phosphoryl bond frequency by adduct formation were first measured by Sheldon and Tyree ${ }^{1,2}$, who also found large negative shifts of the $\mathrm{Se}-\mathrm{O}$ bond frequency in $\mathrm{TiCl}_{4} \cdot 2 \mathrm{SeOCl}_{2}$. Similar effects on the carbonyl bond frequency in ketones have also been reported ${ }^{7,9}$. In all these cases the shift has been caused by interaction with Lewis acids. This does not exclude the possibility, however, that the same effect can be obtained by favourable dipole-dipole interaction.

8. The spectrum with $\mathrm{C}_{5} \mathrm{H}_{5} \mathrm{~N}$ is of particular interest because of the chloride ion transfer processes caused by $\mathrm{C}_{5} \mathrm{H}_{5} \mathrm{~N}$ in $\mathrm{POCl}_{3}$. Gutmann and Baaz ${ }^{10}$ have recently studied the conductances in the similar system $\left(\mathrm{C}_{2} \mathrm{H}_{5}\right)_{3} \mathrm{~N}-\mathrm{POCl}_{3}$ and conclude that the following equilibria exist:

$$
\mathrm{POCl}_{3}+\mathrm{Et}_{3} \mathrm{~N}=\left[\mathrm{POCl}_{2}\left(\mathrm{Et}_{3} \mathrm{~N}\right)^{+} \mathrm{Cl}\right] \text { (ion pair) }=\mathrm{POCl}_{2}\left(\mathrm{Et}_{3} \mathrm{~N}\right)^{+}+\mathrm{Cl}^{-}
$$

The corresponding $K$ values are $2.3 \times 10^{-2}$ and $1.2 \times 10^{-3}$, and it is thus probable that the effect on the spectrum of $\mathrm{POCl}_{3}$ should be small. (The ionic transfer process can in this case not be preceded by a compound formation $\mathrm{POCl}_{3} \cdot \mathrm{Et}_{3} \mathrm{~N}$ because $\mathrm{POCl}_{3}$ has no acceptor properties. The conditions are quite different with $\mathrm{SeOCl}_{2}$ or $\mathrm{AsCl}_{3}$ and amines ${ }^{11}$.) The small shifts obtained with $\mathrm{C}_{5} \mathrm{H}_{5} \mathrm{~N}$ in this case are thus easy to understand. The possibility cannot 


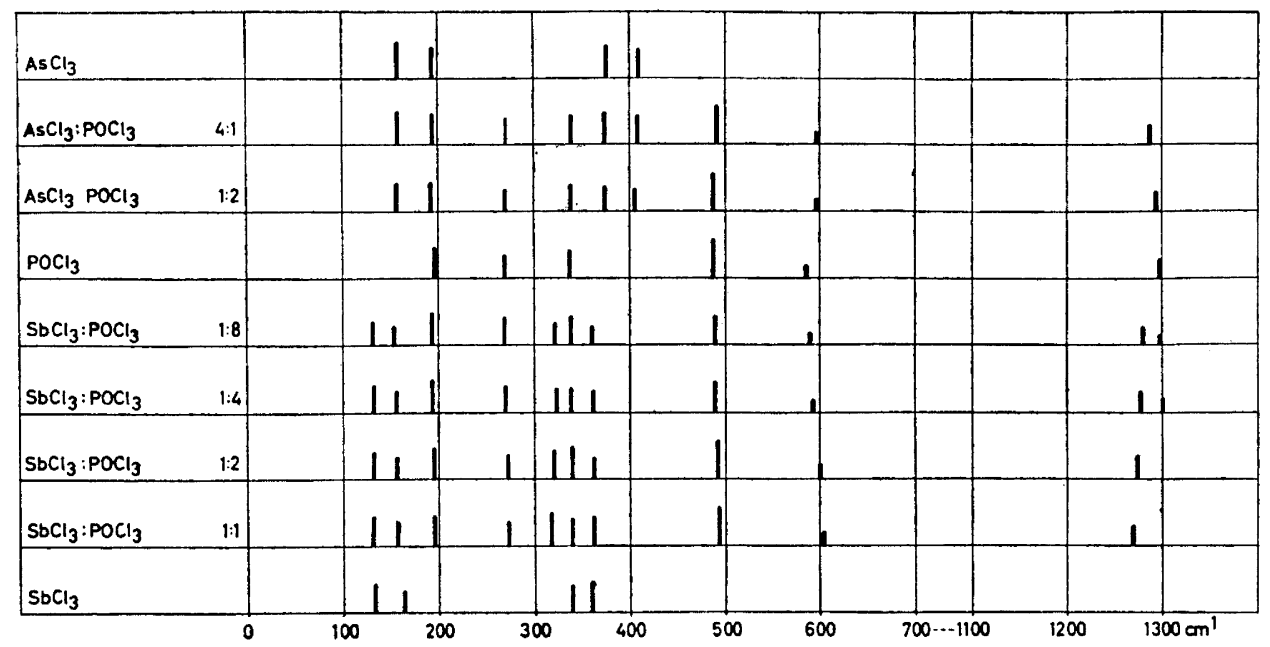

Fig. 2. Raman spectra of the systems $\mathrm{AsCl}_{3}-\mathrm{POCl}_{3}$ and $\mathrm{SbCl}_{3}-\mathrm{POCl}_{3}$.

be excluded, however, that the exceptional influence of $\mathrm{C}_{5} \mathrm{H}_{5} \mathrm{~N}$ on the antisymmetrical P-Cl bond vibration (decrease in frequency instead of increase as obtained with all the other molecules) is associated with a tendency to loosen the P-Cl bond.

\section{RAMAN SPECTRA OF THE SYSTEMS $\mathrm{AsCl}_{3}-\mathrm{POCl}_{2}$ AND $\mathrm{SbCl}_{3}-\mathrm{POCl}_{3}$}

The Raman spectra of solutions with varying mole ratios $\mathrm{AsCl}_{3}: \mathrm{POCl}_{3}$ and $\mathrm{SbCl}_{3}: \mathrm{POCl}_{3}$ are given in Fig. 2. A brief summary and discussion of the results follows.

1. In both systems a continuous change in band positions is found.

2. This change is not connected with any obvious tendency to band broadening. The band profile of the antisymmetrical P-Cl band is slightly altered, however.

3. The continuous change would be expected for a dipole-dipole interaction without formation of stable molecules. The same effect has been reported for the system $\mathrm{H}_{2} \mathrm{O}_{2}-\mathrm{C}_{4} \mathrm{H}_{8} \mathrm{O}_{2}$ where $\mathrm{H}_{2} \mathrm{O}_{2}$ has an exceptional influence upon the dioxane spectrum (over a range of $19 \mathrm{~cm}^{-1}$ ). The authors ${ }^{12}$ comment: "Die Wechselwirkung muss also dynamischer Art sein und von der ganzen Umgebung ausgehen".

4. The $\mathrm{AsCl}_{3}$ spectrum is almost unchanged in the mixtures.

5. The $\mathrm{SbCl}_{3}$ spectrum is changed more in the concentration range studied but not appreciably. The spectrum of liquid $\mathrm{SbCl}_{3}$ (from Kohlrausch, $\mathrm{Hand}$ und Jahrbuch der chemischen Physik, 9:IV, Leipzig 1943) is taken at $+250^{\circ} \mathrm{C}$ and cannot safely be used for comparisons. 

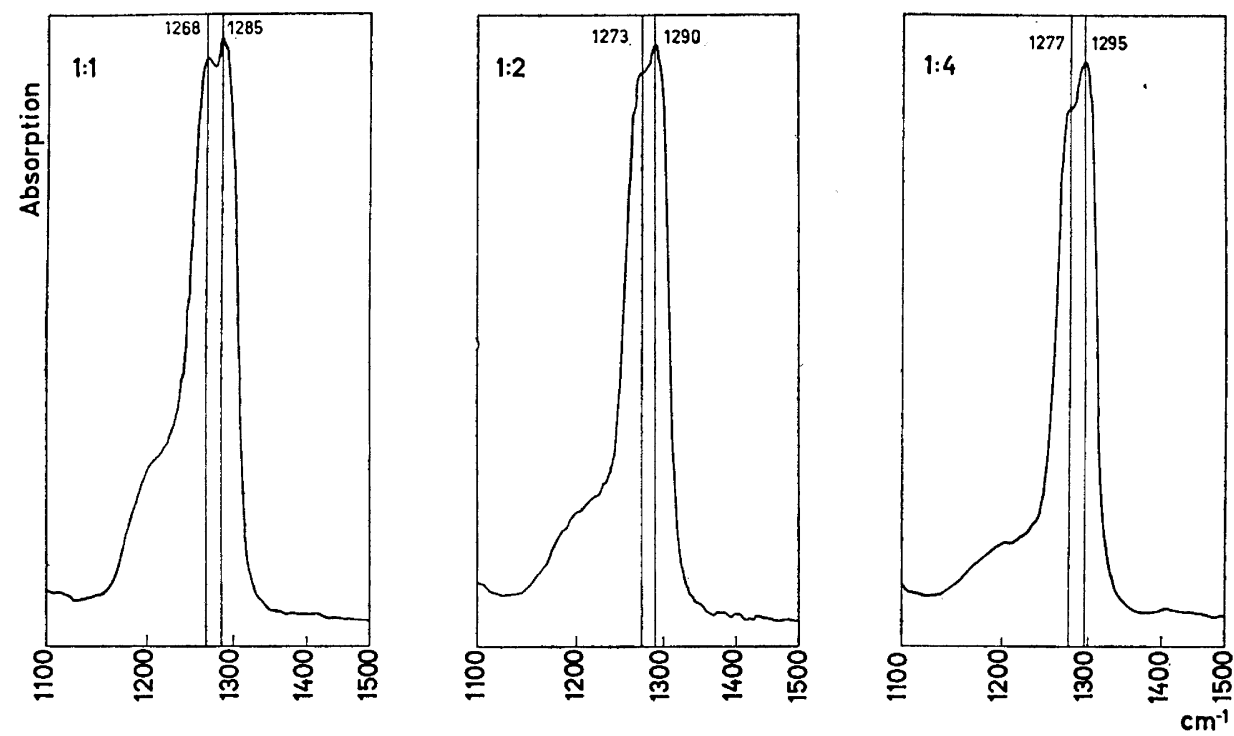

Fig. 3. Infrared spectra, in the phosphoryl band region, of the system $\mathrm{SbCl}_{3}-\mathrm{POCl}_{3}$. The shoulder near $1200 \mathrm{~cm}^{-1}$ is a $\mathrm{POCl}_{3}$ overtone band.

6. The typical Lewis acids usually change their structures by adduct formation with donor molecules like $\mathrm{POCl}_{3}$ (cf. the structure of $\mathrm{SbCl}_{5} \cdot \mathrm{POCl}_{3}{ }^{13}$ ). As a result the spectrum of the acceptor molecule disappears by the adduct formation.

7. In these cases therefore everything indicates dipole-dipole interaction. It would be very interesting to know the structure of the compound $\mathrm{AsCl}_{3} \cdot \mathrm{POCl}_{3}{ }^{11}$ (M.p. $-24^{\circ} \mathrm{C}$ ) to find out whether the formation of the solid compound is also due to electrostatic interaction.

8. The only point of evidence indicating the existence of free and bonded molecules is the double phosphoryl band obtained with excess of $\mathrm{POCl}_{3}$. One band is shifted towards lower frequencies, the other is almost fixed. The latter successively disappears with increasing concentration of $\mathrm{SbCl}_{3}$ and cannot be seen at the composition $\mathrm{SbCl}_{3} \cdot 2 \mathrm{POCl}_{3}$. This evidence will be discussed in the next section.

\section{INFRARED SPECTRA OF THE SYSTEM $\mathrm{SbCl}_{3}-\mathrm{POCl}_{3}$}

Infrared spectra have been taken of all the systems discussed in the preceding section. They have confirmed the Raman spectroscopic results in all cases but one, and are therefore not reproduced here. The exception is the disappearance of the double phosphoryl band at mole ratios $\mathrm{POCl}_{3}: \mathrm{SbCl}_{3}$ smaller than 2:1 (Fig. 3). The trend in the intensity ratio is the same but the intensity of the high frequency band is not reduced as much as in the Raman spectrum. It is actually as strong as the low frequency band even at concentrations where

Acta Chem. Scand. 13 (1959) No. 6 


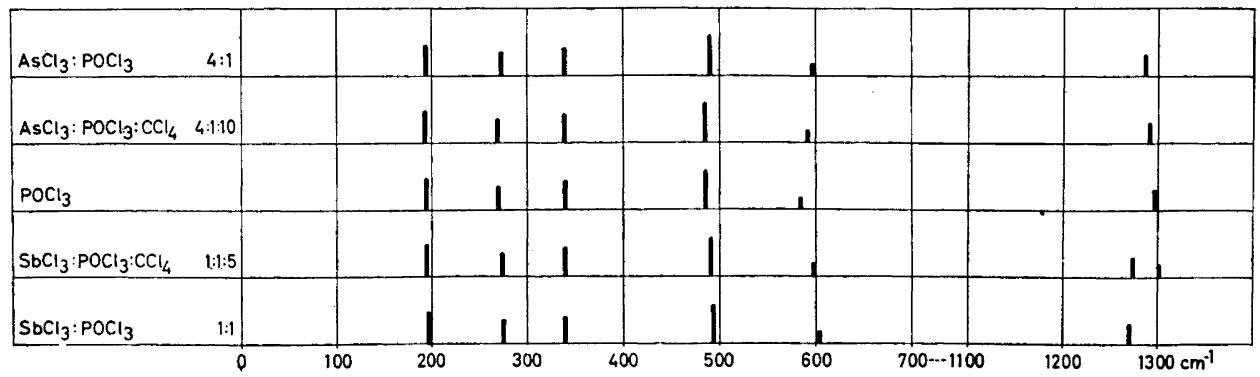

Fig. 4. Raman spectra of solutions in $\mathrm{CCl}_{4}$.

it has disappeared in the Raman spectrum. This indicates that the disappearance in the latter at a composition $\mathrm{SbCl}_{3} \cdot 2 \mathrm{POCl}_{3}$ is purely incidental and is unrelated to compound formation. This result shows the importance of parallel work with Raman and infrared spectra. A study of the phosphoryl band only in the Raman spectrum would in this case have led to a! completely erroneous interpretation.

\section{RAMAN SPECTRA OF MIXTURES $\mathrm{POCl}_{3} \cdot \mathrm{AsCl}_{\mathbf{3}} \cdot \mathrm{CCl}$, AND $\mathrm{POCl}_{\mathbf{8}}-\mathrm{SbCl}_{\mathbf{3}} \cdot \mathrm{CCl}_{4}$}

The Raman spectra of the solutions $\mathrm{POCl}_{3}: \mathrm{AsCl}_{3}: \mathrm{CCl}_{4}=1: 4: 10$ and $\mathrm{POCl}_{3}: \mathrm{SbCl}_{3}: \mathrm{CCl}_{4}=1: 1: 5$ have been studied. The $\mathrm{POCl}_{3}$ bands are shown in Fig. 4 compared with the $\mathrm{CCl}_{4}$-free mixtures.

The spectra indicate a diluting effect of $\mathrm{CCl}_{4}$, reducing the shifts caused by $\mathrm{AsCl}_{3}$ and $\mathrm{SbCl}_{3}$ in agreement with the interpretation as dipole-dipole interaction.

\section{RAMAN SPECTRA OF SOLUTIONS OF STRONG LEWIS ACIDS IN $\mathbf{P O C l}_{8}$}

A preliminary study has been made of solutions of strong acceptor molecules in $\mathrm{POCl}_{3}\left(\mathrm{SbCl}_{5}: \mathrm{POCl}_{3}=1: 20\right.$ and $\left.\mathrm{SnCl}_{4}: \mathrm{POCl}_{3}=1: 9\right)$. The results are shown in Fig. 5 together with the spectra of $\mathrm{SbCl}_{5}$ (from Kohlrausch, Handund Jahrbuch der chemischen Physik, 9:IV, Loipzig 1943), $\mathrm{POCl}_{3}$ and $\mathrm{SnCl}_{4}$. A summary and discussion is given in the following.

1. The spectra of $\mathrm{SnCl}_{4}$ and $\mathrm{SbCl}_{5}$ bave disappeared; as expected for strong Lowis acids.

2. The spectrum of free $\mathrm{POCl}_{3}$ (in excess) is found in both cases as expected for strong compound formation of acceptor-donor type (in contrast to the continuous effect by electrostatic interaction).

3. New bands are formed. These have not been analysed but the knowledge of the exact crystal structure ${ }^{13}$ has opened possibilities for a complete analysis.

4. Some of the free $\mathrm{POCl}_{3}$ bands may also belong to the spectra of the adduct molecules $\mathrm{SbCl}_{5} \cdot \mathrm{POCl}_{3}$ and $\mathrm{SnCl}_{4} \cdot 2 \mathrm{POCl}_{3}$ formed. Infrared spectra 


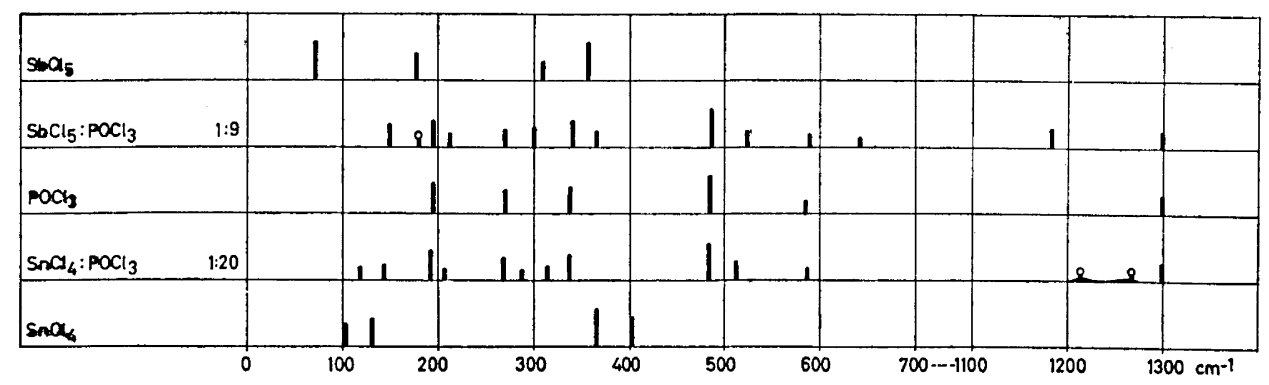

Fig. 5. Raman spectra of solutions of $\mathrm{SbCl}_{6}$ and $\mathrm{SnCl}_{4}$ in $\mathrm{POCl}_{2}$.

of the solid compounds actually show that the phosphoryl band near 1297 $\mathrm{cm}^{-1}$ is also present in the adduct spectra.

5. The phosphoryl band region thus shows two bands with $\mathrm{SbCl}_{5}$ (the maximum shift is $117 \mathrm{~cm}^{-1}$ ), and three bands with $\mathrm{SnCl}_{4}$ (the maximum shift is $85 \mathrm{~cm}^{-1}$ ).

6. Similar large negative shifts with strong Lewis acids have been mentioned earlier in this paper ${ }^{1,2,7,9}$ and the splitting has also been found earlier. Examples of such splitting of carbonyl bands has been given by Susz and Chelandon ${ }^{7,9}$. It has also been reported for the $\mathrm{Se}-\mathrm{O}$ band ${ }^{2}$ in, e.g., $\mathrm{SnCl}_{4} \cdot 2 \mathrm{SeOCl}_{2}$.

7. The opinion that the splitting is due to the existence of two types of donor molecules in the adduct has already been rejected in the introduction to this paper. We have no alternative explanation to offer at present but think that the common occurrence of the splitting should be emphasized.

8. A complicating fact is that the phosphoryl band splitting has also been found in some pure phosphoryl compounds ${ }^{14}$. In those cases the variation is largest in the high-frequency band which has therefore been considered as the typical phosphoryl band.

9. The magnitude of the shift for the lowest frequency phosphoryl band (obtained by the splitting by adduct formation) seems to be a rough measure of the acceptor strength of the acceptor molecule. An interesting survey of the shifts in the carbonyl band has been published recently ${ }^{9}$. If this relation has general validity a very simple method of determining relative acceptor strengths is available. It can, however, only be used if the acceptor molecules to be compared are under very similar conditions.

10. The donor strength of the oxygen atom is not reflected directly in the shifts. The weak donor molecule $\mathrm{SOCl}_{2}$ does not show any shift ${ }^{2}$, but $\mathrm{POCl}_{3}$ gives a larger shift than $\mathrm{POR}_{3}{ }^{1}$ with the same acceptor molecule although the latter without doubt is a stronger donor (cf. the recent assessment of the relative donor strengths of $\mathrm{POCl}_{3}$ and $\left.\mathrm{PO}\left(\mathrm{CH}_{3}\right)_{3}{ }^{15}\right)$. 


\section{CONCLUDING DISCUSSION}

The preceding discussions can be summarized as follows: Negative shifts and splitting of the phosphoryl band can be caused by dipole-dipole interaction as well as by Lewis acid-base reactions. The former will give rise to a general medium effect (the shifts vary continuously with the mole ratios). The latter will lead to formation of kinetically stable adduct molecules (spectra of free and bonded molecules). The spectrum of the acceptor molecule will disappear if its structure is changed by the adduct formation. (This is not a necessary condition with molecules like $\mathrm{HgCl}_{2}$ ).

If this description is correct (it can only be considered as a tentative suggestion) $\mathrm{AsCl}_{3}$ and $\mathrm{SbCl}_{3}$ give favourable dipole-dipole interaction with $\mathrm{POCl}_{3}$ (in contrast to $\mathrm{C}_{6} \mathrm{H}_{5} \mathrm{COCl}$ ), while $\mathrm{SnCl}_{4}$ and $\mathrm{SbCl}_{5}$ give adduct formation by acceptor-donor reactions. It is possible that there exist intermediate cases. We have here deliberately not discussed the nature of the acceptor-donor bond, pending the accumulation of more structural informations, but we intend to study these problems further by spectroscopic and X-ray methods.

A grant from the Swedish Natural Science Research Council is gratefully acknowledged.

Finally we wish to thank Professor S. Cleesson, Professor G. Hägg and Professor A. Tiselius for all facilities put ot our disposal and Mr. S. Bergvall for valuable essistance.

\section{REFERENCES}

1. Sheldon, J. C. and Tyree, S. Y. J. Am. Chem. Soc. 80 (1958) 4775.

2. Sheldon, J. C. and Tyree, S.I Y. J. Am. Chem. Soc. 81 (1959) 2290.

3. Brändén, C. I. and Lindqvist, I. To be published.

4. Dodd, R. E. and Robinson, P. L. Experimental Inorganic Chemistry, Amsterdam 1954, p. $210,216$.

5. Kinell, P.-O. Arkiv Kemi. In press.

6. Bauer, E. and Magat, M. J. phys. radium 9 (1938) 319.

7. Chelandon, P. and Susz, B. P. Helv. Chim. Acta 41 (1958) 697.

8. Terenin, A., Filimonov, W. and Bystrov, D. Z. Elektrochem. 62 (1958) 181.

9. Susz, B. P. and Chelandon, P. Helv. Chim. Acta 41 (1958) 1332.

10. Gutmann, V. and Bara, M. To be published.

11. Agerman, M., Andersson, L. H., Lindqvist, I. and Zackrisson, M. Acta Chem. Scand. 12 (1958) 477.

12. Simon, A. and Fehér, F. Z. Elektrochem. 42 (1936) 688.

13. Lindqvist, I. and Brändén, C. I. Acta Chem. Scand. 12 (1958) 134; Acta Cryst. In press.

14. Bell, J. V., Heisler, J., Tannenbaum, H. and Goldenson, J. J. Am. Chem. Soc. 76 (1954) 5185.

15. Kinell, P.-O., Lindqvist, I. and Zackrisson, M. Acta Chem. Scand. 13 (1959) 190.

Received March 25, 1959. 